Announcement

\section{Community Preventive Services Task Force Recommendation for Interactive Digital Interventions to Improve Blood Pressure Self-Management}

The Community Preventive Services Task Force (CPSTF) recommends interactive digital interventions for blood pressure self-management. "Cardiovascular Disease Prevention: Interactive Digital Interventions for Blood Pressure SelfManagement" is available at https://www.thecommunityguide. org/findings/cardiovascular-disease-interactive-digital-interventions-blood-pressure-self-management.

Established in 1996 by the U.S. Department of Health and Human Services, the CPSTF is an independent, nonfederal panel of public health and prevention experts whose members are appointed by the director of CDC. The CPSTF provides information for a wide range of persons who make decisions about programs, services, and other interventions to improve population health. Although CDC provides administrative, scientific, and technical support for the CPSTF, the recommendations developed are those of the task force and do not undergo review or approval by CDC.

\section{Erratum}

\section{Vol. 66, No. 47}

In the report "Synthetic Cannabinoid and Mitragynine Exposure of Law Enforcement Agents During the Raid of an Illegal Laboratory - Nevada, 2014," on page 1292, the following footnote should have been included with the Table: "*Any level above the lower limit of quantification (LLOQ) for the substance. The LLOQ for AB-PINACA, AB-PINACA $\mathrm{OH}$, and AB-PINACA pent is $0.10 \mathrm{ng} / \mathrm{mL}$; the LLOQ for mitragynine is $1.0 \mathrm{ng} / \mathrm{mL}$." The online version is correct. 